\title{
Racing speed of Thoroughbred horses at different phases of races in Poland
}

\author{
Marta Liss, Izabela Wilk, Sylwester Tkaczyk and Iwona Janczarek \\ Department of Horse Breeding and Use, Faculty of Biology, Animal Sciences and Bioeconomy, University of Life Sciences in Lublin, Poland
}

\begin{abstract}
Summary: The objective of the paper was to present the tactics of a race depending on selected factors. To this end, the tactics were defined with the partial speeds and the average speed of a winning horse in a race. The research material consisted of the race data sheets for the thoroughbreds sourced from the official website of the Polish Jockey Club. The collected data of 347 horses which participated in 1522 races included the total race time for the winner and times for the individual sections of the track (the so-called "quarters"). The database was built considering the following factors: distance and race category, sex and age of horse and period of the racing season. Next, based on the duration and distance of the individual section of the race, the partial speeds and the average race speed were calculated. The race tactics were described with the names taken from the sets of terms used to characterize mathematical curves. Furthermore, the relation between the horses' speed over the individual race quarters was determined taking in consideration the distance of a race as the factors that determine most of the time parameters of horses during races. The data was processed with an analysis of variance for repeatable measurements. t-Tukey's test and Pearson's correlation coefficient were determined. It was found that the race tactics are largely individual, whereas the speed during its individual phases is most often interrelated. However, it is possible to establish common features for different types of tactics and assign specific levels of external factors to them. The distinguished groups can be compared to mathematical curves, e.g. a sinusoid (mainly for the races for the three-year-old and older horses and for the races for mares) or a parabola (mainly for short-distance and classic races and races during the second phase of the racing season). The knowledge of these types may help assess the racing performance in horses which will be especially helpful for trainers, riders and owners.
\end{abstract}

Keywords: horses, races, speed, race tactics, Thoroughbred

Citation: Liss M., Wilk I., Tkaczyk S., Janczarek I. (2018) Racing speed of Thoroughbred horses at different phases of races in Poland. Pferdeheilkunde 34, 454-460; DOI 10.21836/PEM20180507

Correspondence: Dr. Izabela Wilk, Department of Horse Breeding and Use, University of Life Sciences in Lublin, Akademicka 13, 20-950 20-950 Lublin, Poland; izabela.wilk@up.lublin.pl

\section{Introduction}

Horse racing generates the highest profits in the equine industry in Europe and worldwide (Wincewicz-Bosy 2011), with trotter's races being particularly popular in Scandinavia and France and flat races that are most appreciated in England, USA, Germany and other countries (racing.ustrotting.com 2017, www. vet-trot.eu/en 2017). Regardless of the racing types, the victory in a race is determined by many factors and relations between them (Janczarek et al. 2017, Houpt 2011 , Sobczy ska 2004, 2006, Lambert et al. 2002, Janczarek 2001, Kapro et al. 2001, Biedermann and Bickel 1985), of which the most important include the origin of horses, age, sex, nutrition and care and stress-reducing measures associated with appropriate training methods (Curtis 1999). It was found that, for thoroughbreds, age had a positive impact on the speed (Biedermann and Bickel 1985) while the analyses carried out by Sobczyríska (2003) did not confirm the correlation between the speed and final place in a race and the age of horses. The results of published studies also indicate that the sex of horse exerts a substantial impact of the time result in a race (Mota et al. 1998, Buttram et al. 1988). Better results are expected in colts. The definition of appropriate training not only includes the above-mentioned balanced ratio of exercise load, but also the selection of a rider, favourable racing conditions (weather conditions, quality of a racetrack or the potential of competing horses) and the so-called proper race tactics, i.e. the way the horse is ridden by a rider over a specific section of a racetrack depending on its individual predispositions and external factors occurring during a race (lvers 1994).
The horse trainer is responsible for developing the tactics (Gardner 2006) that must be further discussed with a rider. The common view says that the tactics should be adjusted to the type of race, horse breed, sex, the month of the racing season and many different aspects that may directly affect the result of horse in a race (Ivers 1994). Determining the speed over the subsequent sections of a race is the basic element of the tactics. Since the speed should not be lower than the speed that is used as a factor categorizing the race, a performance trial necessary to meet the selection criteria, while it should not be excessively strenuous for a horse and it should permit accelerating the speed over the home stretch to get the best place possible (Sobczyríska 2011).

The paper assumes that there are at least some standards, despite the need for developing an individual tactic for each horse, with which the tactics can be described. This assumption resulted in the objective of the paper, i.e. to present the tactics of a race for Thoroughbreds depending on the selected factors. To this end, the tactics are expressed as the speed of a winning horse over the individual sections of a racetrack.

\section{Material and methods}

The analysis was based on the compilations of thoroughbred race data sheets in the 2015 racing season sourced from the official website of the Polish Jockey Club of 347 horses which participated in 1522 races (the bookmark: Racing reports) (www.pkwk.pl, 2016). The collected data included the dura- 
tion of a race for the winning horse over the individual sections of the racetrack (the so-called quarters, i.e. the consecutive sections of 500 metres each), yet from the home line, the racetrack length must cover the complete 500 meters of a quarter whereas the first quarter after the start is lengthadjusted to the total race distance. For instance, for a 1,800 $\mathrm{m}$ distance, the distribution of quarters is as follows: 1st quarter (after the starting line) $=300 \mathrm{~m}, 2$ nd quarter $=500 \mathrm{~m}, 3 \mathrm{rd}$ quarter $=500 \mathrm{~m}$, and 4 th quarter $=500 \mathrm{~m}$. The database was built based on the following factors (Table 1):

1 Race distance (level 1 =short-distance races: $1,000-1,300 \mathrm{~m}$, level $2=$ medium-distance races: $1,400-1,800 \mathrm{~m}$, level 3 =classic-type distance races $(2,000-2,400 \mathrm{~m})$;

2 Race category (level no. 1: A category=the highest rank: B category, level 3: group 1 and 2, level 4: group 3 and 4 = the lowest rank);

3 Sex of competing horses (level 1 = colts, level 2 = fillies);
4 Age of competing horses (level $1=$ horses in their first racing season, i.e. two-year-old horses, level $2=$ threeyear-olds and older horses);

5 Part of the racing season (level $1=$ the first part - until the Derby Day, i.e. the first Sunday in July, level 2 = the second part - after the Derby Day).

Next, based on the duration and distance of the individual quarters, the average speed of horse $(\mathrm{m} / \mathrm{s})$ over these sections and the average race speed were calculated, considering all analysed factors. The race tactics were described with the names taken from the sets of terms used to characterize mathematical curves (Bourbaki 2013) and they were then assigned to the analysed factors and their respective levels. The final stage of the analyses served to determine the correlation between the speed of horses over the individual quarters of a races, considering its distance as the factor with the most determining impact on the time performance results of the horses (Binns et al. 2010).

Table 1 The number of horses depending on the analysed factor and its level

\begin{tabular}{cccccc}
\hline \multicolumn{7}{c}{ Quarter } \\
\hline 1 & 2 & 3 & 4 & 5 & Total race duration (s) \\
\hline
\end{tabular}

Race distance

Short-distance races: 1,000-1,300m

79

79

65

Medium-distance races: 1,400-1,800m

131

131

Classic-type races: $2,000-2,400 m$

$46 \quad 46$

Race category

A category

14

14

14

9

3

14

B category

16

16

16

9

5

16

Group 1 and 2

80

80

69

26

2

80

Group 3 and 4

146

146

143

93

8

146

Sex of horses

Colts

151

144

94

12

151

Fillies

105

105

98

43

6

105

Age of horses

Two-year-olds

56

56

45

4

56

Three-year-olds and older

200

200

197

133

18

200

Part of the racing season

The first part (before the Derby Day)

69

67

48

8

69

The second part (after the Derby Day) 
Statistical methods

Before starting a statistical method the data were verify with regard to the normality of distribution. Four different methods of testing the distribution were applied (Shapiro-Wilk, Kolmogorov-Smirnov, Cramer-von Mises, Anderson-Darling). Almost all tests did not reject the hypothesis on the normality of the data distribution. None of the parameter data was rejected by all of the tests at a level high enough (0.01). The data was processed with an analysis of variance for repeatable measurements with the SAS statistical software (O'Rourke and Hatcher 2013). The analysed factors and their interaction were considered. The significance of differences was described with t-Tukey's test and the correlations were determined with Pearson's coefficient.

\section{Results}

For the race distance factor, significant differences were found between the average values for both the comparable distances, yet different quarters, and the same quarter but in races over different distances (Table 2). It was found that, regardless of the race distance, the speed of the horses over the first quarter of the race was substantially lower than the speed over the other quarters for which the speed was comparable, except for a significantly higher speed over the fifth quarter in over $2,000 \mathrm{~m}$ races. The highest speed was recorded in short races. The speed in consecutive quarters was more similar in short- and medium-distance races than in the classic-type races.

Regardless of the race category, the speed of the horses over the first quarter of the distance was significantly lower than the speed over the other quarters (Table 3). In the other cases, the speed of the horses over the subsequent racetrack sections was mostly similar. No significant differences were noted between the means for the same quarters in different race categories.

Both for the colts and fillies, the speed over the first quarter of the racetrack was significantly lower than the speed over the other quarters (Table 4). Significant differences were also found between the fifth and the average colts speed and the second quarter and the average mare speed. The speed over these quarters was higher than the average speed for colts and fillies. No differences were demonstrated between colts and fillies for the speed over the same quarters.

For the age factor, a significantly lower speed was recorded in all horsesover the first racetrack quarter in comparison with the other quarters. Significant differences were also found

Table 2 Speed $(\mathrm{m} / \mathrm{s})$ of the horses over the individual sections of the racetrack, depending on the race distance

\begin{tabular}{|c|c|c|c|c|c|c|}
\hline & \multicolumn{6}{|c|}{ Quarter } \\
\hline & 1 & 2 & 3 & 4 & 5 & Average race speed \\
\hline & \multicolumn{6}{|c|}{ Short-distance races: $1,000-1,300 \mathrm{~m}$} \\
\hline Mean & $15.02^{\mathrm{ax}}$ & $16.56^{\mathrm{bx}}$ & $16.11^{\mathrm{bx}}$ & - & - & $16.07^{b x}$ \\
\hline \multirow[t]{2}{*}{ SD } & 0.92 & 0.49 & 0.69 & - & - & 0.39 \\
\hline & \multicolumn{6}{|c|}{ Medium-distance races: $1,400-1,800 \mathrm{~m}$} \\
\hline Mean & $13.89^{\text {ay }}$ & $16.22^{\mathrm{bxz}}$ & $16.03^{b x}$ & $16.02^{\mathrm{bx}}$ & - & $15.83^{\mathrm{bxz}}$ \\
\hline \multirow[t]{2}{*}{ SD } & 1.72 & 0.66 & 0.57 & 0.60 & - & 0.40 \\
\hline & \multicolumn{6}{|c|}{ Classic-type races: $2,000-2,400 \mathrm{~m}$} \\
\hline Mean & $14.37^{\mathrm{az}}$ & $15.86^{\text {byz }}$ & $15.71^{\mathrm{bx}}$ & $15.99^{\mathrm{bx}}$ & $16.28^{c}$ & $15.63^{\text {byz }}$ \\
\hline
\end{tabular}

Table 3 Speed $(\mathrm{m} / \mathrm{s})$ of the horses over the individual sections of the racetrack, depending on the race category

\begin{tabular}{|c|c|c|c|c|c|c|}
\hline \multicolumn{7}{|c|}{ Quarter } \\
\hline & 1 & 2 & 3 & 4 & 5 & Average race speed $(\mathrm{m} / \mathrm{s})$ \\
\hline \multicolumn{7}{|c|}{ A Category } \\
\hline Mean & $14.10 a x$ & $16.49 b x$ & $16.02 \mathrm{bx}$ & $16.32 \mathrm{bx}$ & $16.58 \mathrm{bx}$ & $16.00 b x$ \\
\hline SD & 1.31 & 0.78 & 0.57 & 0.50 & 0.41 & 0.43 \\
\hline \multicolumn{7}{|c|}{ B Category } \\
\hline Mean & $14.40 \mathrm{ax}$ & $16.42 b x$ & $16.33 b x$ & $16.51 \mathrm{bx}$ & $16.31 \mathrm{bx}$ & $16.11 \mathrm{bx}$ \\
\hline SD & 1.32 & 0.64 & 0.45 & 0.42 & 0.32 & 0.36 \\
\hline \multicolumn{7}{|c|}{ Group 1 and 2} \\
\hline Mean & $14.60 \mathrm{ax}$ & $16.33 \mathrm{bx}$ & $16.01 b x$ & $16.07 \mathrm{bx}$ & $15.69 \mathrm{bx}$ & $15.92 \mathrm{bx}$ \\
\hline SD & 1.42 & 0.59 & 0.62 & 0.60 & 0.63 & 0.45 \\
\hline \multicolumn{7}{|c|}{ Group 3 and 4} \\
\hline Mean & $14.19 a x$ & $16.18 b x$ & $15.94 \mathrm{bx}$ & $15.91 \mathrm{bx}$ & $16.29 \mathrm{bx}$ & $15.80 \mathrm{bx}$ \\
\hline SD & 1.60 & 0.68 & 0.63 & 0.59 & 0.60 & 0.41 \\
\hline
\end{tabular}

The means (rows: $a, b, c$; columns: $x, y, z$ ) denoted with different letters differ significantly at $P \leq 0.05$ 
between the second and fourth racetrack quarter in races with two-year-old horses and between the second and fifth quarter in races with three-year-old horses and older.

Both in the first and second part of the racing season, the speed over the first quarter was substantially lower than the speed over the other quarters (Table 6). In the first part of the season, significant differences were also found for the second quarter and the average race speed while in the second part of the season, the differences were noted for the fifth quarter and the average race speed. No differences were found for the speed of horses over the same quarters during the subsequent parts of the racing season.
Based on the speed of horses over the individual quarter of the race, the following five race tactics were distinguished and to which the analysed factors and their levels were then assigned (Table 7).

Most significant correlations between the speed over the individual racetrack sections in the races of different distances was found when the horses competed over the 2,000-2,400m track (Table 8). The significant coefficients were mostly positive and associated with a relation between the last quarters or the last quarters and the total race duration. The least significant correlations were found for shortdistance races, i.e. those over 1,000-1,300 m.

Table 4 Speed $(\mathrm{m} / \mathrm{s})$ of the horses over the individual sections of the racetrack, depending on the sex of a winning horse

\begin{tabular}{|c|c|c|c|c|c|c|}
\hline \multicolumn{7}{|c|}{ Quarter } \\
\hline & 1 & 2 & 3 & 4 & 5 & Average race speed $(\mathrm{m} / \mathrm{s})$ \\
\hline \multicolumn{7}{|c|}{ Colts } \\
\hline Mean & $14.36 a x$ & $16.23 b x$ & $16.00 \mathrm{bx}$ & $16.00 \mathrm{bx}$ & $16.36 \mathrm{bcx}$ & $15.87 \mathrm{bdx}$ \\
\hline SD & 1.40 & 0.71 & 0.55 & 0.57 & 0.50 & 0.43 \\
\hline \multicolumn{7}{|c|}{ Fillies } \\
\hline Mean & $14.28 a x$ & $16.30 b c x$ & $15.97 b d x$ & $16.04 \mathrm{bx}$ & $16.11 \mathrm{bx}$ & $15.87 \mathrm{bdx}$ \\
\hline SD & 1.68 & 0.59 & 0.71 & 0.66 & 0.56 & 0.42 \\
\hline
\end{tabular}

The means (rows: $a, b, c$; columns: $x, y, z$ ) denoted with different letters differ significantly at $P \leq 0.05$.

Table 5 Speed $(\mathrm{m} / \mathrm{s})$ of the horses over the individual sections of the racetrack, depending on the horse age

\begin{tabular}{|c|c|c|c|c|c|c|}
\hline \multicolumn{7}{|c|}{ Quarter } \\
\hline & 1 & 2 & 3 & 4 & 5 & Average race speed $(\mathrm{m} / \mathrm{s})$ \\
\hline \multicolumn{7}{|c|}{ Two-year-old horses } \\
\hline Mean & $14.85 a x$ & $16.21 \mathrm{bcx}$ & $15.94 b x$ & $15.18 \mathrm{bdx}$ & - & $15.85 b x$ \\
\hline SD & 1.24 & 0.52 & 0.63 & 0.22 & - & 0.43 \\
\hline \multicolumn{7}{|c|}{ Three-year-old horses and older } \\
\hline Mean & 14.18ay & 16.27bcy & 16.00by & 16.03by & $16.28 \mathrm{bc}$ & $15.87 \mathrm{bdx}$ \\
\hline SD & 1.56 & 0.70 & 0.61 & 0.59 & 0.52 & 0.42 \\
\hline
\end{tabular}

The means (rows: $a, b, c$; columns: $x, y, z$ ) denoted with different letters differ significantly at $P \leq 0.05$.

Table 6 Speed $(\mathrm{m} / \mathrm{s})$ of the horses over the individual sections of the racetrack, depending on the part of the racing season

\begin{tabular}{lcccccc}
\hline & \multicolumn{7}{c}{ Quarter } \\
\hline & 1 & 2 & 3 & 4 & 5 & Average race speed $(\mathrm{m} / \mathrm{s})$ \\
Mean & $14.18 \mathrm{ax}$ & $16.45 \mathrm{bcx}$ & $16.12 \mathrm{bx}$ & $16.15 \mathrm{bx}$ & $16.25 \mathrm{bx}$ & $15.99 \mathrm{bdx}$ \\
SD & 1.45 & 0.67 & 0.48 & 0.46 & 0.31 & 0.36 \\
\hline Mean & $14.38 \mathrm{ax}$ & $16.19 \mathrm{bx}$ & $15.94 \mathrm{bx}$ & $15.93 \mathrm{bx}$ & $16.30 \mathrm{bcx}$ & $15.83 \mathrm{bdx}$ \\
SD & 1.55 & 0.65 & 0.66 & 0.65 & 0.66 & 0.44 \\
\hline
\end{tabular}

The means (rows: $a, b, c$; columns: $x, y, z$ ) denoted with different letters differ significantly at $P \leq 0.05$.

\begin{tabular}{lll}
\hline Table 7 & List of the race tactics and the assigned levels of the analysed factors \\
\hline No. & Name of tactics & Assigned factors and their levels \\
\hline 1. & Sinusoidal & Three-year-old horses and older, fillies \\
2. & Parabolic & Short-distance races and classic-type races, second part of the racing season, races of group 3 and 4 \\
3. & Regressive & Two-year-old horses, group 1 and 2 \\
4. & Straight & Fillies, second part of the racing season \\
5. & Incremental & Medium-distance races, first part of the season, A category, B category \\
\hline
\end{tabular}




\begin{tabular}{|c|c|c|c|c|c|c|}
\hline \multicolumn{7}{|c|}{ Correlations between the speed $(\mathrm{m} / \mathrm{s})$ over the individual racetrack sections in the different types of races } \\
\hline \multicolumn{7}{|c|}{ Short-distance races: $1,000-1,300 \mathrm{~m}$} \\
\hline Quarter & 1 & 2 & 3 & 4 & 5 & Average race speed \\
\hline 1 & - & 0.213 & 0.078 & - & - & 0.022 \\
\hline 2 & - & - & & - & - & -0.121 \\
\hline 3 & - & - & - & - & - & 0.217 \\
\hline 4 & - & - & - & - & - & $0.567^{*}$ \\
\hline 5 & - & - & - & - & - & $0.669^{*}$ \\
\hline Total race time & - & - & - & - & - & - \\
\hline \multicolumn{7}{|c|}{ Medium-distance races: $1,400-1,800 \mathrm{~m}$} \\
\hline Quarter & 1 & 2 & 3 & 4 & 5 & Average race speed \\
\hline 1 & - & -0.102 & 0.089 & 0.123 & - & 0.126 \\
\hline 2 & - & - & 0.104 & 0.022 & - & 0.094 \\
\hline 3 & - & - & - & -0.067 & - & 0.111 \\
\hline 4 & - & - & - & - & - & -0.007 \\
\hline 5 & - & - & - & - & - & $0.542^{*}$ \\
\hline Total race time & - & - & - & - & - & - \\
\hline \multicolumn{7}{|c|}{ Classic-type races: $2,000-2,400 \mathrm{~m}$} \\
\hline Quarter & 1 & 2 & 3 & 4 & 5 & Average race speed \\
\hline 1 & - & -0.056 & 0.105 & 0.089 & 0.044 & 0.123 \\
\hline 2 & - & - & -0.041 & 0.222 & $0.589 *$ & 0.099 \\
\hline 3 & - & - & - & $0.459^{*}$ & 0.109 & $0.559^{*}$ \\
\hline 4 & & & & & $0.678^{*}$ & $0.601^{*}$ \\
\hline 5 & & & & & & $0.458^{*}$ \\
\hline Total race time & & & & & & - \\
\hline
\end{tabular}

\section{Discussion}

Many external factors are found to impact the distribution of speed in Thoroughbreds over the individual racetrack sections. The lowest speed is the only common feature over the so-called first quarter of the race, which was in the $100-400 \mathrm{~m}$ range for the analysed races. Similar results for the speed of racing horses in the initial phase of a race were reported by Estberg et al. (1996) who found that this resulted from the need to take the most favourable position for the horse among the competing horses and not from competing to take the winning position.

According to Evans and McGreevy (2011), the fight for a win usually takes place in the last phase of the races, i.e. over $500 \mathrm{~m}$ before the finish line. However, the results presented in the paper are not fully consistent with this conclusion since such relation applies only to the races over 2,000-2,400m distance. In shorter races, the horses achieve the highest speed at the mid-race distance, which is most probably due to the fact the classic-type races are entered by the best horses, capable of speeding up significantly in the final stage of a race. A similar view is shared by Schurink et al. (2009). The results for the type of race factor also confirm the impact of the racing class of a horse on the racing tactics. The last phase of a race is run at the highest speed in A category races, i.e. the highest category. Importantly, the races of group 3 and 4 should also be mentioned, since for these races the distribution of speed over the subsequent race phases is simi- lar, even though the horses entering such races are not the best horses; this may result from the fact that these horses reach lower speeds in earlier parts of a race due to a capacity- and strength-saving mechanism. The results of the analyses are thus considered consistent with the findings published by Sobczyriska (2011).

The impact of horse age on the tactics of a race is also worth discussing. For the colts, the speed in the initial and final phase of a race is comparable and highest whereas the fillies keep the highest speed in the first phase of a race and the speed then slightly decreases and stays at a similar level up to the finish line. It seems that this fact is determined by the higher prowess of colts, which allows them to concentrate their strength before the finish. A similar view is presented by Wilsher et al. (2006). The need to concentrate strength in the final stages of a race is also demonstrated by the results for the age factor. The speed of the two-year-olds decreases with consecutive stages of a race whereas this phenomenon is not seen in three-year-old horses and older, unsurprisingly, as the body of a two-year-old horse is still not fully developed in terms of capacity (Curtis 1999) and therefore it is not possible to maintain the equally high speed over the whole race distance or to increase speed in the finishing phase. Furthermore, the role of the second part of the racing season in modelling the speed in consecutive stages of a race is emphasized. It is found that the only basic difference is a substantially lower speed of horses competing in the second part of the racing season in comparison with the first part; appa- 
rently, after a couple of months in competition, the crucial factor lays in the fatigue of horses and other factors influencing the specific tactics of a race. Higher galloping speed in the first part of the racing season is also discussed by Dyson et at. (2008). The results presented in the paper are thus considered consistent with the referenced findings.

\section{Conclusion}

To draw some conclusions from an analysis of the results, it is worth emphasizing that the tactics of a race are largely individual while the speed in its individual phases is most often not related. However, it is possible to determine the common features of different types of tactics and to assign them to the specific levels of external factors. The distinguished types can be compared to mathematical curves, e.g. a sinusoid (mainly for races for three-year-olds and older horses and for races for fillies) or a parabola (mainly for short-distance and classic races, the races during the second phase of racing season and low-category races). The knowledge of these types may help to assess the racing performance in horses.

\section{References}

Biedermann G., Bickel M. (1985) Die Vererbung der Rennleistung in der deutschen Vollblatzucht. Züchtungsk. 57, 293-298

Binns M. M., Boehler D. A., Lambert D. H. (2010) Identification of the myostatin locus (MSTN) as having a major effect on optimum racing distance in the Thoroughbred horse in the USA. Anim. Genet. 41, 154-158; DOI 10.1111/i.1365-2052.2010.02126.x

Bourbaki N. (2013) Algebra II: Chapters 4-7. Springer Science \& Business Media

Buttram S., William R. L., Wilson D. E. (1988) Genetics of racing performance in the American Quarter Horse: II Adjustment, factors and contemporary groups. J. Anim. Sci. 66, 2800-2806; DOI 10.2527/jas1988.66112800x

Curtis S. (1999) Farriery: foal to Racehorse. RW Pubns Ltd.

Dyson P. K., Jackson B. F., Pfeiffer D. U., Price J. S. (2008) Days lost from training by two- and three-year-old Thoroughbred horses: $A$ survey of seven UK training yards. Equine Vet. J. 40, 650-657; 10.2746/042516408X363242

Estberg L., Stover S. M., Gardner I. A., Drake C. M., Johnson B., Ardans A. (1996) High-speed exercise history and catastrophic racing fracture in thoroughbreds. Am. J. Vet. Res. 57, 1549-1555

Evans D., McGreevy P. (2011) An investigation of racing performance and whip use by jockeys in Thoroughbred races. PloS one 6, e15622; DOi 10.1371/journal.pone.0015622
Gardner D. S. (2006) Historical progression of racing performance in thoroughbreds and man. Equine Vet. J. 38, 581; DOi $10.2746 / 042516406 \times 156514$

Houpt K. A. (2011) Domestic animal behaviour for veterinarians and animal scientists. John Wiley \& Sons.

Ivers T. (1994) The fit racehorse II. Equine Res. Publ. Texsas, USA

Janczarek I. (2001) Parametry oceny zaawansowania treningowego koni wy cigowych. PhD thesis. University of Life Sciences in Lublin.

Janczarek I., Wilk I., Strzelec K. (2017) Correlations between body dimensions of young trotters and motion parameters and racing performance. Pferdeheilkunde 33, 139-145; DOi 10.21836/ PEM20170205

Kapro M., Janczarek I., Suska A., Czerniak E. (2001) Wpływ jako ci toru oraz temperatury powietrza na wska niki dzielno ci wy cigowej koni pełnej krwi angielskiej. Roczniki Nauk. Zootech. 14, 133-141

Lambert G. W, Reid C., Kaye D., Jennings G. L., Esler M. D. (2002) Effect of sunlight and season on serotonin turnover in the brain. Lancet, 360, 1840-1842; DOI 10.1016/S0140-6736(02) $11737-5$

Mota M. D. S., Oliviera H. N., Silva R. G. (1998) Genetic and environmental factors that affect the best time of Thoroughbred horses in Brazil. J. Anim. Breed. Gene. 115, 123-129; DOI 10.1111 /i.1439-0388.1998.tb00335.x

O'Rourke,N., Hatcher L. (2013) A step-by-step approach to using SAS for factor analysis and structural equation modelling. Sas Institute

Schurink A., Theunissen M. C. J., Ducro B. J., Bijma P., van Grevenhof E. M. (2009) Identification of environmental factors affecting the speed of purebred Arabian racehorses in The Netherlands. Livestock Sci. 125, 97-100; DOI 10.1016/j.livsci.2009.03.004

Sobczyńska M. (2003) Wpływ wybranych czynników rodowiskowych na u ytkowo (dzielno ) wy cigow polskich koni pełnej krwi oraz przydatno tych mierników do oceny tej u ytkowo ci. Prac. Materiat. Zootechn. 61, 49-59

Sobczyńska M. (2004) Wpływ efektu trenera na dzielno wy cigow koni pełnej krwi i czystej krwi arabskiej w zale no ci od dystansu i rangi gonitwy. Zesz. Nauk. Przegl du Hodowl. 72, 145-153

Sobczyńska M. (2006) Zale no mi dzy wybranymi czynnikami a dzielno ci wy cigow koni pełnej krwi angielskiej i czystej krwi arabskiej. Prace i Materiał. Zootechn. 63, 81-89

Sobczyńska M. (2011) Environmental factors affecting the speed of Thoroughbred horses competing in Poland. Animal Sci. Pap. Rep. 29, 303-312

Wilsher S., Allen W. R., Wood J. L. N. (2006) Factors associated with failure of Thoroughbred horses to train and race. Equine Vet. J. 38, 113-118; DOI 10.2746/042516406776563305

Wincewicz-Bosy M. (2011) Wy cigi konne jako element gospodarki wiatowej. Zeszyły Naukowe Szkoły Głównej Gospodarstwa Wiejskiego w Warszawie. Probl. Rolnict. wiatow. 11.

www.pkwk.pl, 2016.

www.racing.ustrotting.com, 2017.

www.uet-trot.eu/en, 2017. 